\title{
Eco-Cultural Solution to the Challenge of Waste Generation at Individual Level: Case Study from India
}

\section{Satya Prakash Mehra*}

Rajputana's Shakuntalam, Village Ramnagar, PO Malah, Bharatpur, Rajasthan, India

\begin{abstract}
Indian culture has the affinity for the conservation of nature and natural resources on the concepts of Aranya Samskruti (Forest Culture) and Prakruti Purush (Nature Man). The eco-culture could be observed through the ongoing customs and traditions prevalent in the Indian society. These age-old practices represent a symbiotic relationship of Man and Nature. The paper highlighted the philosophy of eco-ethics of the then society.

The pace of development changed the life style of every human throughout the globe. The impacts were also observed among the Indian Society. High energy demanding society replaced the low energy demanding society. The eco-concepts lost their relevance. The rise in demand resulted into the consumerist society with the advent of "Use and Throw" mentality of human society leading towards a challenge of waste generation.

The Indian System had the age old practices of 3R's (Reduce, Reuse, Recycle) which was environmental friendly. With the advancement of consumerism, 3Rs lost their relevance and resulted into one of the biggest environmental challenges of waste production. The paper further highlighted the eco-compatible Indian cultural traits towards such issues.

Learning from the customs, traditions and rituals, the paper discussed the relevance of those practices which could be the possible solution to cope up the challenge of waste management at individual level. Case study of the campus of the authors had been briefed where the age old conservation practices had been revived leading towards the natural solutions for the environmental challenges. In continuance of the present action oriented research, the authors lead a way to understand the relevance of waste for the avifaunal biodiversity through their extensive research in different parts of country. The detailed work had been carried forward in the other paper. The traditional ecological knowledge which is site-specific has the global application which needs to be converted into the sustainable developmental initiatives through policy formulation.
\end{abstract}

Keywords: Human; Nature; Environment

\section{Introduction}

\section{Importance of the theme}

The human being is distinguished from an animal through his culture. The culture of humans is well defined in the customs, traditions and rituals prevalent in any society throughout the globe. None of the indigenous culture is away from the nature's rule. The eco-concepts are primary feature of every culture of the human society. There should not be second thought in stating that every nation of the world had rich traditions embedded in the ethics of protecting nature. Historically, the ancient cultures presented a picture of the then communities who lived in harmony with nature and a tradition of reverence for the elements that constituted ecosytems, drawing their sustenance from natural resources and at the same time protecting the environment that sustained them. With the influence of cross cultural learning, the indigenous culture always goes change. The changes can be positive or negative. But generally, one can find the external influence as the foreign invasion which is not in accordance to the local ecological setup. This affects the local socio-ecological setup negatively. The subsequent paragraphs have tried to highlight the issue of waste linked with the cultural aspects of the humans with reference to Indian society.

\section{Indian philosophy}

Since the earliest known literature, the Vedas under the aegis of the then saints, the philosophy of the Indian society was focused on the simple life paths which were treated basic rules to live with nature and its component. The rules were impartial for all the living beings based on the principles of symbiotic relationship, the Aranya Samskruti (Forest
Culture) and Prakruti Purush (Natural Man which means human as per nature's rule). The well documented eco-concepts in the Vedas under the experiential researches of the then Rishi Muni (saints and sages) resulted into the customs, rituals and traditions. These rules guided and gave direction to every individual of the then Indian society towards roles and responsibilities from individual to the global level. Since the prime objectives of such rules was to give the directions to led a life as according to the nature's rule, therefore, sustainable development was key feature of such principles. The individual's focus was fulfillment of his basic need required to sustain the life along with complete utilization and retention of the resources. The "Use and Reuse" of every resource was a prominent feature of the society. It could be observed even in the modern Indian society till date especially in the rural communities. The ideology was very simple, i.e., to utilize the available resource till it gets down to its simplest form re-available for nature to get part of natural cycle in the shortest period of time. Since the resource was having the biodegradable nature, therefore, it was obvious that degradation was the faith of the resource without generating a waste. In fact, as per the

*Corresponding author: Mehra SP, Rajputana's Shakuntalam, Village Ramnagar PO Malah, Bharatpur 321001 Rajasthan, India, Tel: +91 9414165690; E-mail: drspmehra@yahoo.com

Received June 24, 2017; Accepted July 04, 2017 ; Published July 11, 2017

Citation: Mehra SP (2017) Eco-Cultural Solution to the Challenge of Waste Generation at Individual Level: Case Study from India. Int J Waste Resour 7: 288 doi: 10.4172/2252-5211.1000288

Copyright: ( 2017 Mehra SP. This is an open-access article distributed under the terms of the Creative Commons Attribution License, which permits unrestricted use, distribution, and reproduction in any medium, provided the original author and source are credited. 
philosophy of the Indian society, there was nothing like waste due to the concepts of "Yog" (=add on) stating towards "Upyog" (=use and reuse). Under such eco-ethical concepts, the human was "Yogi" or say "Karmyogi" (=worker). Activities and actions in accordance to natural setup led an eco-friendly lifestyle of the then humans [1-3].

As per the cultural traits, Indian society is well aware of the segregation and disposal of wastes at the point source inherited in the traditional knowledge of "zero waste". The Indians are well trained to store wet and dry waste separately. In the Indian concern, the wastes used to be treated at the point sources before it gets mix in the external environment [1-3]. The bio-wastes were consumed by animals or kept at the site where natural decomposition takes place. In absence of the space, there used to be a community site for collection of solid biowastes. These community bio-wastes were treated as sacred site. One of the rituals of Indian marriage ceremony is "Ghoora Pujan" or "Kachra Pujan" (worshipping the waste). The reason of paying respect to wastes is to know the importance and value of the waste. Besides, the broomstick which is commonly used by the Indian made of the grass species or the date palm leaves get the due respect in the daily routine. Also, it is being associated with the Goddess of Wealth. The Indian festival of Diwali has special rituals for the broomstick and considered auspicious to procure. The bio-waste cattle dung has another day of rituals. The "Govardhan Puja" (worshipping the mountain of cattle dung) after the main Diwali festival in Braj Region of Northern India is another example of recognizing value of bio-wastes (Figure 1). In true sense, the ceremonial steps of the Govardhan are the preparation of the culture medium for bacteria. This culture is then spread in the agriculture fields. The belief might be considered as the superstitious but one can't overlook the relevance of the rituals associated with cleanliness and value of bio-wastes through such practices by every Indian since aegis. The non-biodegradable materials such as plastic bags and plastics were not the part of the Indian society. Instead, carry bags formed from the old clothes (reuse of clothes) or the plant materials (grasses like bamboo) were the feature till its replacement by plastics. The carry bags of clothes, if get deteriorated these were used for cleansing purpose (wiping clothes) till it gets degraded to its lowest form. The papers or newspapers use to be transferred for reuse or recycle. Many types of glasses and metallic articles were recycled. Thus, there was hardly any content left at the end to be thrown out the house in the Indian Society of 20 th century.

\section{Challenges}

The eco-ethical philosophy of the Vedic age in India got altered with the influence of the external agencies along with the pace of development. Ever increasing population which resulted in migration of people, urbanization along with technological interventions contributed to an increase in quantity of wastes. The advancement of the modern technosciences developed materials of comfort for humans. This led to the "Waste", with the inception of the concept, "Use and Throw". As a nation urbanizes and the population becomes wealthier, the consumption of non-biodegradable materials (e.g. plastics, glass, metals) increases with a decrease in biodegradable fraction $[4,5]$. Globally the estimated quantity of municipal waste generation is over 1.3 billion tonnes per year which is likely to increase 2.2 billion tonnes per year by $2025[5,6]$. Thus in the modern times, solid waste generation could be associated with the economic status of a society [6]. A city resident generates twice as much waste as their rural counterpart of the same affluence [4].

The modern Indian society is not untouched with such trends, the culture of "Upyog" (=use; on the concept of reuse, reduce, recycle) is

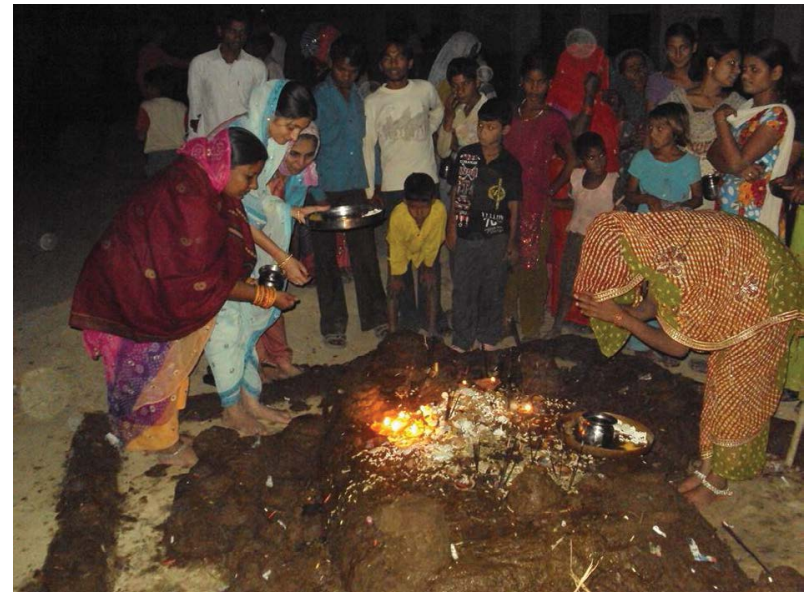

Figure 1: Govardhan puja (collective or community collection of cattle dung to prepare the mixture which could be used as resource) at Bharatpur, Rajasthan, India.

being replaced by the attitude of "Upbhog" (consumeristic approach) which is leading a way towards increase in waste generation [2,3,7]. It is estimated that every day India is generating $\sim 6 \%$ of the total municipal wastes generated by Asian nations [8]. In India, 300 to 400 gms of solid waste per person per day in town of normal size with an increase of 500 to 800 gms per capita per day in cities like Delhi and Bombay is produced. Other than the solid waste, disposal of domestic sewage which accounts $\sim 29,000$ MLD from urban areas is the biggest challenge [9]. As a result of discharge of domestic sewage, the surface water bodies and the streams, rivers are directly polluted whereas indirectly underground water table gets affected.

The problem in big cities is how to dispose and manage such large quantity of solid and liquid waste daily and this poses a massive and expensive problem to the authorities. The conditions are grievous, untreated waste have the direct negative impact on the surrounding environment leading a way to indirect negative impacts all across the globe. The situation is alarming and need immediate attention to reduce the waste. It is now global concern to find out the eco-friendly, economic feasible solution to sustain natural characteristics of environment. In case of municipal wastes, this probability of possible solutions is higher only when there is check and control at individual level or at point source. The NIMBY (Not In My Backyard) syndrome of solid waste disposal could be converted into YIMBY (Yes In My Backyard) concept with the use of indigenous approaches. The subsequent illustration has tried to present a picture of approach adapted at individual level or point source using the eco-cultural traditional knowledge of waste management.

\section{Possible Solutions}

In the age of information, approach of modern man had overruled the native concepts of living. The indigenous and customary rules are treated as the act of primitive, backward and superstitious community. The traditional knowledge of the native and indigenous communities are hardly become part of modern policies despite of the fact that they have a tremendous understanding of ecology and the sustainability. Thus, contribution of the ethnic aspects in the waste management needs to be reconsidered in the modern times to overcome the present challenges of ever increasing wastes. The composition of municipal solid waste in India is $51 \%$ organics, $17.5 \%$ recyclables (paper, plastic, metal, and glass) and $31 \%$ of inerts [10]. Similarly, liquid waste water 
which includes all the sewage coming out of the houses, but not limited to municipal, all other draining out unutilized liquids changing natural characteristics of water. The authors dealt with the biodegradable parts of the waste of both the physical states - Biodegradable or organic solid waste and Biodegradable liquid waste.

\section{Solution at point source}

While considering the age old practices, solid bio-wastes could be treated at the individual or at the community/ cooperative housing society levels. The segregated bio-wastes are decomposed using the traditional composting techniques. The simplest method of composting developed by Daily Dump, PBK Waste Solutions Pvt. Ltd. (http:// dailydump.org/about-us/) could be exemplified for the disposal of waste at point source level (individual as well as housing society/ community). Images are taken from the "Human Kind Foundation" presentations (Figures 2-4).

The waste water treatment is also based on the age old practices of phytoremediation, i.e., passing waste water through the plant species of native origin. In the modern period, it has been modified at various levels and known by several names such as reed bed system (RBS) or

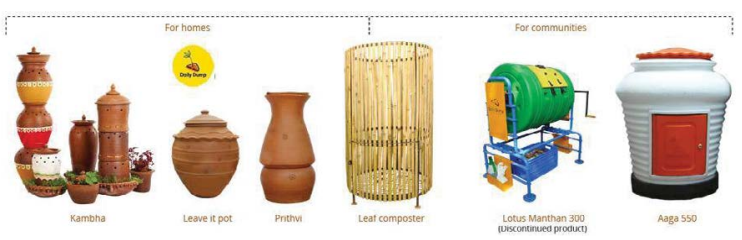

Figure 2: Solid waste management at individual level and community level.

\section{so

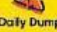 \\ $4 / 3$ tier terracotta composter}

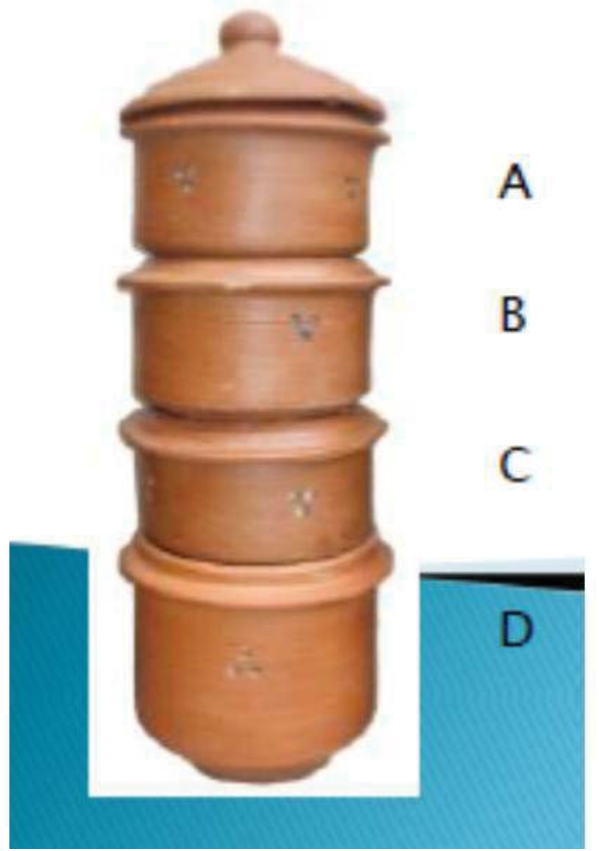

Figure 3: Individual level house composting through terracota composter.

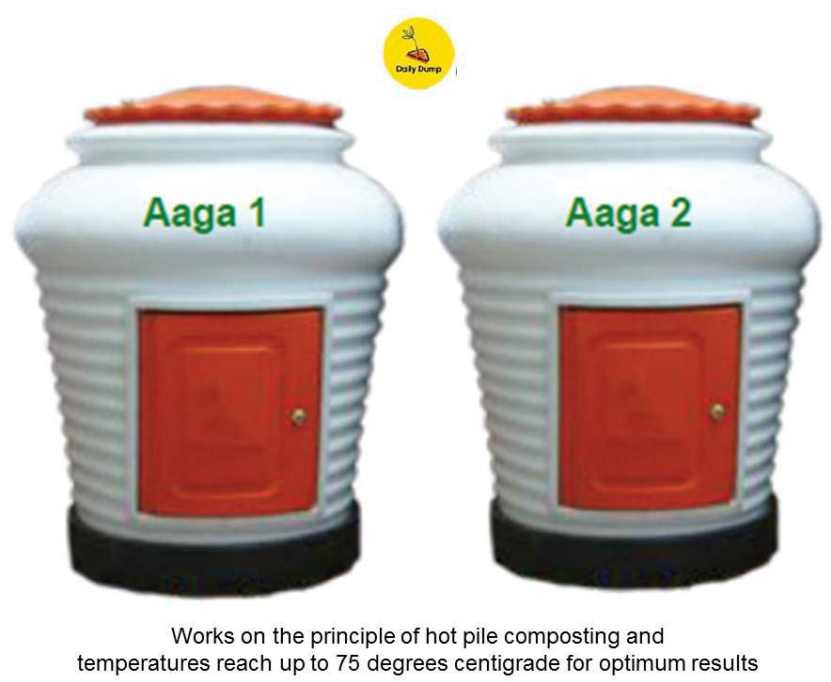

Figure 4: Community level composting through aaga composter

soil infiltration beds or constructed wetlands. The technique is well used by the Natural Solutions (http://www.naturalsolutions.org.in/) which could be exemplified. The source of images is Photo Library of Natural Solutions, Mumbai (Figures 5 and 6).

The author has created a centre in village Ramnagar, adjoining World Heritage and Ramsar Site - Keoladeo National Park, Bharatpur, Rajasthan, India. The centre is example of the "zero waste" where the demonstration of composting methods at individual levels are displayed and practiced. The images are taken from the RSNH Photo Library (Figure 7).

The RSNH team under mentorship of author surveyed waste disposal sites (landfills and dumping grounds) and the waste water logged sites to assess the avifaunal diversity [11]. It was found that the sites harbored over fifty bird species. The commonest bird species recorded from the terrestrial waste disposal sites were Black Kite (Milvus migrans), Cattle Egret (Bubulcus ibis), House Crow (Corvus splendens), etc. Among the globally important species, Egyptian Vulture (Neophron percnopterus) had shown its presence. In the waste water sites, Blackwinged Stilt (Himantopus himantopus) was the commonest of all. Among the migratory species, Northern Shoveler (Anas clypeata) was the commonest one to observe from the waste water sites.

\section{Conclusion}

Owing to the decentralized governance in India along with participatory research on waste management at individual level signifies a broader shift in thinking. The centralized governance had undertaken the individual's perspective with due consideration in the policy development through different modes. "Swacch Bharat Mission" (Clean India Mission) is one of the great initiatives taken by the Central Government towards the waste management. On the occasion of the World Environment Day (5 June 2017), Central Government has launched a movement through local municipal bodies to encourage segregation at the individual levels before collection. The mission could be made successful through involvement of every citizen through reviving the age-old practices of zero or minimum waste generation. If waste is generated than segregation and using the bio-wastes as resource. 


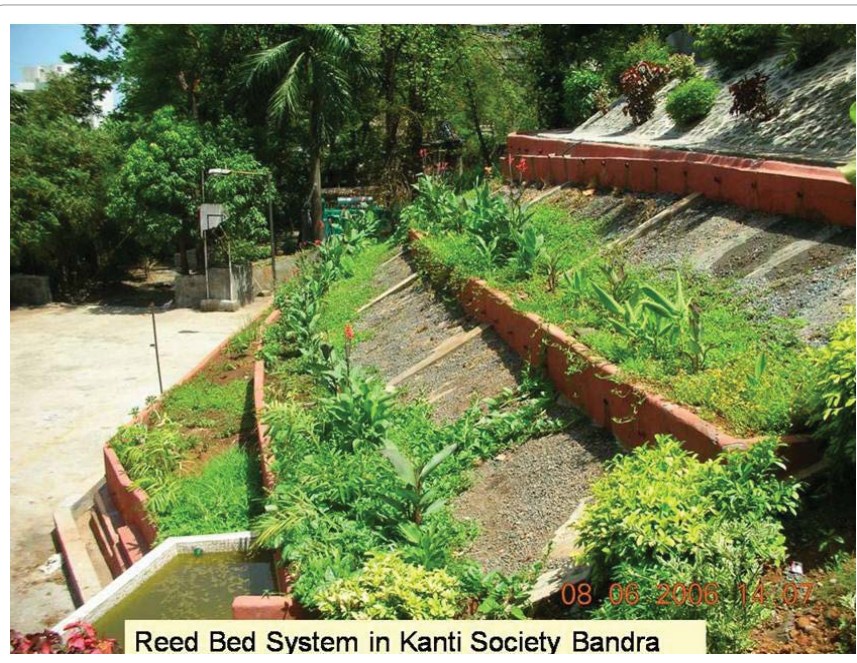

Figure 5: Treatment of waste water in kanti housing society, Bandra, Maharastra, India.

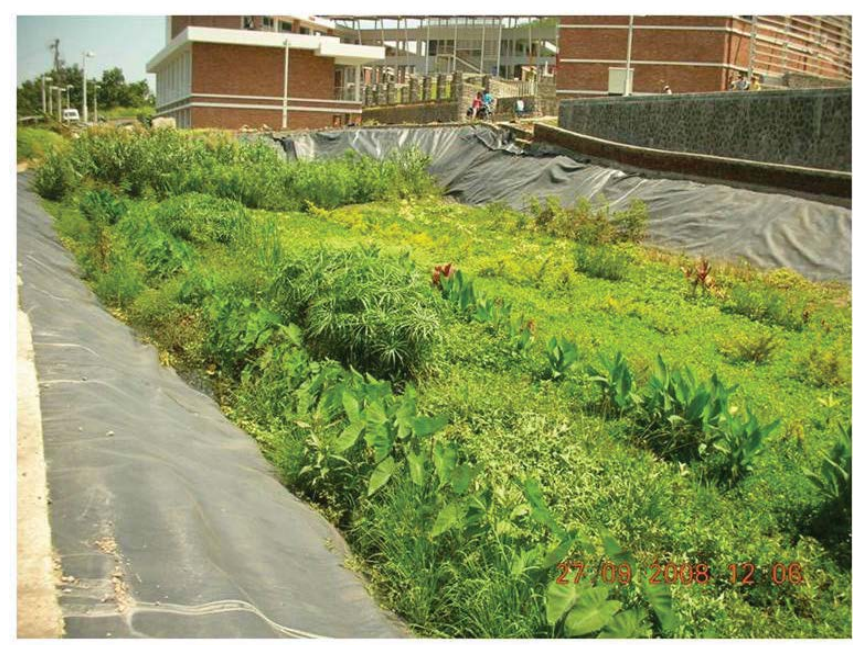

300,000 lit/day Composite Sewage Reed Bed System Symbiosis Knowledge Village, Lavale, Pune

Figure 6: Natural treatment system of composite sewage water at symbiosis knowledge village, Pune, India.

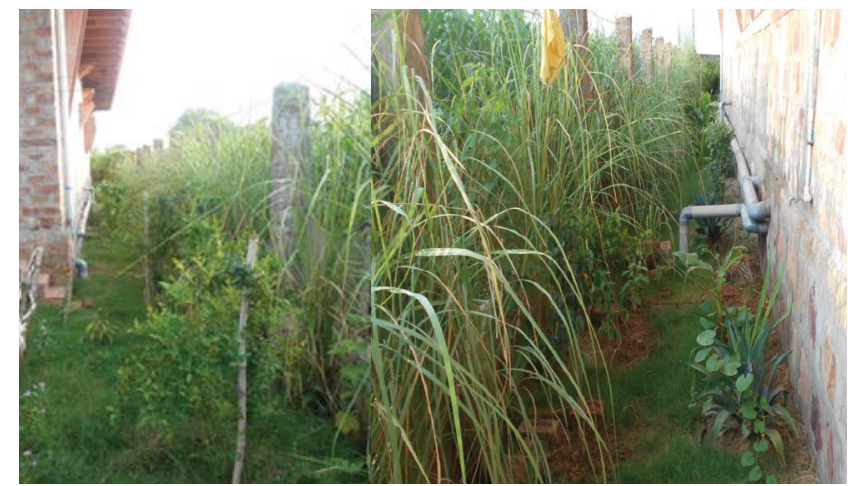

Figure 7: Waste water treatment at individual level (RSNH Centre, Rajputana's Shakuntalam, Village Ramnagar, Bharatpur, Rajasthan, India).

\section{References}

1. Hamilton S (2001) Indian Philosophy: A Very Short Introduction. Oxford University Press, US

2. Perrett RW (2001) Indian Philosophy: Metaphysics. Taylor \& Francis, UK.

3. Coward HG (2012) Perfectibility of Human Nature in Eastern and Western Thought. SUNY Press, US.

4. Hoornweg DA, Bhada-Tata P, Kennedy C (2013) Environment: Waste Production must Peak this Century. Nature 502: 615-617.

5. Bhada TP, Hoornweg DA (2012) What a Waste? A Global Review of Solid Waste Management. Urban Development Series Knowledge Papers; no. 15. World Bank Group, Washington, DC.

6. Yoshizawa S, Tanaka M, ShekdarAV (2004) Global Trends in Waste Generation TMS Mineral, Metals and Materials Publishers, Spain. pp: 1541-1552.

7. Emerald ND (2004) Consumerism, Nature and Human Spirit. MS Research Dissertation. Virginia Polytechnic Institute and State University, USA.

8. Pappu A, Saxena M, Asolekar SR (2007) Solid Wastes Generation in India and their Recycling Potential in Building Materials. Building and Environment 42 2311-2320.

9. Anon (2005) Status of Sewage Treatment in India. Central Pollution Contro Board, New Delhi.

10. Annepu RK (2012) Sustainable Solid Waste Management in India. MSc Dissertation, Columbia University, New York.

11. Mehra SP, Mohib U, Verma V, Sharma H, Singh TT (2017) Avifaunal Diversity of the Waste Dumping Sites and Waste Water Bodies. 